\title{
Palestinian Census 2017 - Harnessing the Modernization Initiative
}

\author{
Ola Awad ${ }^{\mathrm{a}, *}$ and Sufian Abu Harb ${ }^{\mathrm{b}}$ \\ ${ }^{a}$ President of Palestinian Central Bureau of Statistics, Palestine \\ ${ }^{\mathrm{b}}$ Assistant Undersecretary for Services Sector at PCBS, Palestine
}

\section{Introduction}

Population and housing censuses play a key role in providing detailed data on the characteristics of the population and its housing conditions at the community levels. Census operations are typically very complex and seen as the most demanding operation a statistical bureau may undertake.

The implementation of a census in any country is a legal and developmental necessity. In Palestine, it is also an exercise of sovereignty and determination to mark informatics independence.

Palestine was on a date to undertake its third Population, Housing and Establishment Census on December $1^{\text {st }} 2017$ which was the reference date for the population count. The 2017 Census was the proper vehicle for providing crucially needed data for effective planning and for the integration of demographic indicators into the overall development planning process. The Palestinian decision to carry out the census in its normal periodicity (1997, 2007 and 2017) came in response to our awareness of the crucial need for a very detailed level of statistics to establish a rigorous baseline to monitor the Sustainable Development Goals (SDGs). Census data were also essential to complement the findings of the Expenditure and Consumption survey 2017 to produce multidimensional poverty indicators. Such combined data, once integrated into a well-designed geographical information system, will produce geographically based poverty

\footnotetext{
*Corresponding author: Ola Awad, President of Palestinian Cen-
} tral Bureau of Statistics, Palestine. E-mail: ola@pcbs.gov.ps. pockets in Palestine. This is a direct response to a core requirement of the SDGs. However, grasping these opportunities is not always as simple as it sounds.

\section{Palestine's context}

The normal conditions, as set by the United Nations, to carry out a census include controlled borders, a defined geographical area, political stability, free movement, and a positive public perception. Applying these conditions to the Palestinian case would definitely negate the possibility of undertaking such a project as Palestine is fragmented into areas $\mathrm{A}, \mathrm{B}$ and $\mathrm{C}$ (with varying Palestinian control); the annexation and separation wall separates Palestinian land, and Gaza is under siege.

Theoretically, connecting these dots on paper will give a zero feasibility of census undertaking in Palestine. However, the profile of PCBS as the provider of Palestine's official statistics refutes such a theory as PCBS has managed to conduct two population censuses, one agriculture census and five establishment censuses since 1993. The competencies on which the Palestinian statistical system resides collectively support the production of high quality official statistics to enlighten the public and to serve the Palestinian citizenry. These competencies are not new, but rather the result of a long standing of good strategic planning and unlimited support from the government, the research and academic communities, as well as the public at large. The international community has paid great attention to this national exercise. Such attention has 
taken various forms including generous financial support, technical cooperation and moral support of partners.

Census undertaking in Palestine has clearly reflected a unique collaborative spirit. The consensus on census content resulted from a structured consultation of all stakeholders. The final census content reflected national priorities and responded to the need for scientific data to support National Policy Agenda 2017-2022 and SDGs.

\section{Modernization initiative}

PCBS started the modernization of its statistical system including infrastructure and techniques since 2010. The modernization process has covered data collection methods with increasing focus on electronic means. Since 2010, PCBS has implemented more than 50 surveys using handheld devices and tablets covering all continuous surveys such as the Labor Force Survey and the Consumer Price Index (CPI), as well as periodic surveys such as Economic Series Surveys and the Living Conditions Survey. The practices on the ground have triggered the transfer to the Generic Business Process Model (GSBPM) as a basis for the statistical project cycle to accommodate for the very details of the different processes.

The following conditions had influenced PCBS' decision to move gradually to electronic data collection since 2010:

- Geographical separation between the West Bank and the Gaza Strip and the difficulties related to the transfer of paper questionnaires between the two parts.

- Limitations to the free movement of persons due to permanent or temporary checkpoints between localities, in addition to, the separation wall that surrounds Palestinian localities.

- The vulnerability of the confiscation of paper questionnaires at checkpoints and the impact on public perception in relation to privacy and data confidentiality.

It was very clear to us that the move to the use of new technologies was not an end goal but an integrated part of overall modernization that targeted people, technology, practices and methodologies. A strategic key objective was to build organizational capacity cumulatively as a snowball to align well with the vision of the national statistical system.

\section{The uniqueness of the 2017 census}

The 2017 census was different in many aspects compared to previous censuses in Palestine. The census harnessed the results of the 2010 modernization initiative. The census utilized latest technology as it employed tablets for data collection and integrated Geographical Information Systems (GIS) in the different processes of the census including census planning, data processing, data collection, data analysis and dissemination. The 2017 census was based on GIS technologies to add managerial value (i.e. tracking of enumerators and monitoring coverage) and technical value (i.e. quality control and geospatial analysis) to the different stages of census undertaking.

As for census scenarios and related decision factors, four scenarios were thoroughly examined in 2014 for the use of electronic data collection in the 2017 census:

- The first scenario was to apply electronic data collection to all census stages: updating of base maps, delineation of enumeration areas, marking and listing of buildings and housing units, the population count, as well as the post-enumeration survey. This scenario would require about 10,000 tablets in the count stage.

- The second scenario was to apply the technology to specific phases of the census project, mainly in the marking and listing phase, which would reduce the number of tablets to less than 2000 instead of 10,000 .

- The third scenario was to go for electronic data collection in specific governorates in order to reduce the level of potential risks.

- The fourth scenario was to conduct a traditional paper-based census.

The factors that influenced PCBS' decision on the type of data collection included:

- Being in-line with the PCBS modernization initiative.

- Secure tablets at a low cost or on a lending basis.

- Providing digitized base maps for use in future surveys and sampling frames.

- The ability to share digitized maps with stakeholders to ensure value for money.

- A GIS - based census to monitor fieldwork activities (operation wise) and link data geographically (dissemination wise) to meet the data needs of stakeholders and partners.

- Improving data quality based on previous experience in applying electronic data collection. 
- Overcoming challenges attached to fieldwork operations (mobility of fieldworkers, transport of paper questionnaires etc.).

After mapping the proposed scenarios with the decision factors, PCBS took the decision in 2014 of fullscale electronic data collection in the 2017 census. On this basis, the 2017 census exhibited characteristics, which differ from previous censuses:

\subsection{Technology-driven census}

Census data were collected using tablets supported by GIS technology. The decision-making process for using electronic data collection technologies in the census was based on contextual facts related to Palestine's conditions on the ground rather than for the sake of using technology per se.

Among the factors that were not in favour of electronic data collection was the G2 cellular network in Palestine, which would add extra cost and prevent the full utilization of electronic data collection, as well as the broadband coverage. However, PCBS' experience in implementing surveys in the field using electronic data collection technologies proved the Bureau's ability to cope with such limitations (i.e. use of the offline data collection option).

By using a customized Fieldwork Management and Control System, PCBS was able through its field offices and headquarter to review and validate the data at both (individual and aggregate) levels simultaneously as it was transmitted from the field. The system provided reports on productivity and performance indicators through tables, charts and electronic maps. It also provided interactive reports to keep census headquarter and census fieldwork supervisors informed of problematic areas.

The incorporation of GIS technology in the census allowed the census management including the central office, census governorate directors, supervisors and crew leaders to monitor enumerators' progress per enumeration area using online and offline GPS tracking of enumerators' daily movements.

The technology has also improved the work distribution of fieldworkers. More than 7000 enumerators worked on the population enumeration phase of the census, in addition to, supervisors and crew leaders. Assignment of enumeration areas for each enumerator was predefined prior to the fieldwork phase in the data collection application. GIS technology ensured no overlap in the enumerators' areas of work. With each supervisor responsible for five crew leaders, and each crew leader supervising five enumerators, such management hierarchy was also reflected in the flow of data in the data collection application.

\subsection{Cost-conscious census}

The use of electronic data collection technologies in PCBS has reduced the cost of each survey by about 20 percent of the total survey cost. The decision on the type of data collection method used in the census was in favour of the electronic technique provided that tablets were to be provided at no cost after an agreement was reached with the Jordanian Department of Statistics to borrow more than 7000 tablets. This opportunity saved about 5 million Dollars from the Palestinian census budget. The tablets were transported back to Jordan after the completion of the census in Palestine.

In addition, equipment needed to provide internet services for census training halls were secured on a lease basis from internet providers (part of the service contract) and IT equipment provided for the Bureau's data center was part of the IT infrastructure upgrade strategy and not for the census per se.

\subsection{Documentation of the experience}

A special documentation and archiving team was established at the beginning of census preparations. The task of this team was to document every aspect of the census undertaking, including but not limited to, the decision-making process, census committees, design of the census methodology, interaction with the public at large, the publicity campaign, resource mobilization, census training, and field encountered difficulties due to the use of technology in data collection etc.

\subsection{Modernization of the whole cycle}

The modernization process has not only covered hardware and software issues but has also targeted practices to improve accountability and transparency in the training and selection of fieldworkers. Internet connectivity was provided to all fieldwork-training centers. Daily quizzes and final exams were conducted online. The selection of fieldworkers was based on their marks in the quizzes and the final evaluation exams and that process was managed centrally and electronically. Internet connectivity was provided to all local supervision offices to allow supervisors to track the progress of fieldworkers. 


\subsection{Partnership-driven census}

The 2017 census reflected actual partnerships with all stakeholders including local communities, government institutions, the private sector, as well as international organizations.

PCBS underwent consultations with all stakeholders on the census content to ensure that the 2017 census addressed national priorities. Regular meetings with donors were conducted to keep partners on board on census progress and challenges.

A Donors Advisory Group was formed after the census undertaking to keep donors informed of census data utilization and of the PCBS statistical program.

\section{Lessons learned}

Censuses of Population, Housing, and Establishments are crucial undertaking in the life of any country. In Palestine, the census project provided temporary job opportunities for more than 10,000 university graduates. This was of great value in a country with a high unemployment rate reaching about 30 percent. In the Gaza Strip alone, more than 25,000 applicants competed for only 2000 census fieldwork opportunities.

Technology pays off well when it is used to support census undertaking in an integrated matter covering the whole project cycle rather than in a fragmented fashion. Technology was present in the whole census cycle including various fieldwork phases, training of fieldworkers, selection of fieldworkers, dissemination of census results using data visualization techniques, and documentation of the census project.

The opportunity to borrow the tablets rather than purchasing them conveyed clear messages to the government, partners and the donor community that:

- PCBS is a cost conscious organization.

- The modernization process of PCBS' infrastructure was crowned by the state of the art census undertaking including aspects such as electronic data collection, GIS-based census.

- PCBS was able to send a crystal-clear message to government institutions in Palestine that: despite the challenges on the ground, there are always different ways to achieve your goals.

The application of electronic data collection at the bureau since 2010 was a progressive process, which started by targeting specific surveys, as well as specific geographical areas. The selection of surveys that would be carried out using electronic data collection was based on specific criteria which took into account the competence of the survey manager, the frequency of the survey (in favour of regular surveys such as the labour force survey), and a pre-test as part of the project work plan. The progressive implementation smoothed the transformation of the bureau to electronic data collection setup in anticipation of the 2017 census.

Moving from paper-based censuses to electronic ones required the re-engineering of the various census processes such as the design of the questionnaires, the tasks of the fieldwork teams, and the introduction of technical support (IT) staff as part of the fieldwork teams. One issue of importance was the volume of validation rules in the data collection application and their impact on the expected interviewing time. A balanced approach was necessary to honor a data collection time plan, data quality and the dissemination schedule. A Post Enumeration Survey (PES) was conducted in January 2018 to measure census coverage. Tablets with enumeration area maps and online editing rules were used to implement the PES.

The involvement of stakeholders through committees and regular meetings to convey key messages on census progress was very beneficial (i.e. the involvement of the different governors or mayors was crucial in facilitating fieldwork activities in terms of resource mobilization or advocacy of public cooperation). PCBS hired publicity coordinators in each governorate to support the implementation of the census communication strategy.

Regional and international cooperation provided unlimited opportunities for technical cooperation, transfer of expertise and sharing of resources. This proved very beneficial for the census such as the ability to borrow tablets from Jordan and to benchmark good census practices from different countries including Brazil, Jordan and Egypt.

The census project was a success due to long-term planning and awareness of the surrounding environment. PCBS announced the census results in March 2018 using state-of-the-art dissemination techniques (i.e. data visualization, animation and infographics). The census dissemination plan included the production of a Public Use File that comprised a 20 percent sample, analytical studies by independent researchers, an electronic atlas and statistics covering small areas.

Ola Awad is President of the Palestine Central Bureau of Statistics and former President of the International Association of Official Statistics (2015-2017). She holds a doctorate in Business Administration from 
the University of Liverpool, UK and an MA in Business Administration and Management from Boston University.

Sufian Abu Harb is the Assistant Under-Secretary for Services Sector at the Palestinian Central Bureau of Statistics. He holds an MBA degree from Birzeit University and a BSc in Computer Science from Canada.

\section{References}

[1] Abu Harb, S. Palestine is counting. This Week in Palestine, [online] (235). 2017. Available at: http://thisweekinpalestine. com/issue-archive/?issue $=235$.
[2] Awad, O. Aligning Global Initiative to National Agenda: The Challenge of SDGs. This Week in Palestine, [online] (235). 2017. Available at: http://thisweekinpalestine.com/issuearchive/?issue $=235$.

[3] Laaribi, A, Peters, L. GIS and the 2020 Census: Modernizing Official Statistics. ESRI Press, 2019.

[4] Palestinian Central Bureau of Statistics (PCBS). Census 2017 Final Results - Summary [Internet]. Ramallah; 2018. Available from: http://www.pcbs.gov.ps/Downloads/book2369.pdf.

[5] United Nations. Handbook of Statistical Organization [Internet]. 2003. Available from: https://unstats.un.org/unsd/ publication/SeriesF/SeriesF_88E.pdf. 